\section{Clustering of risk factors for cardiovascular disease among women in Southern Brazil: a population-based study}

\author{
Agregação de fatores de risco para doenças \\ cardiovasculares em mulheres no Sul do Brasil: \\ um estudo de base populacional
}

\author{
1 Faculdade de Medicina, \\ Universidade Federal do Rio \\ Grande do Sul, Porto Alegre, \\ Brasil. \\ 2 Instituto de Ciências Básicas \\ da Saúde, Universidade \\ Federal do Rio Grande do Sul, \\ Porto Alegre, Brasil. \\ ${ }^{3}$ Hospital de Clínicas de \\ Porto Alegre, Universidade \\ Federal do Rio Grande do Sul, \\ Porto Alegre, Brasil. \\ 4 Instituto de Matemática, \\ Universidade Federal do Rio \\ Grande do Sul, Porto Alegre, \\ Brasil \\ Correspondence \\ S. C. Fuchs \\ Departamento de Medicina \\ Social, Faculdade de \\ Medicina, Universidade \\ Federal do Rio Grande do Sul. \\ Rua Felipe de Oliveira 987, \\ apto. 901, Porto Alegre, RS \\ 90630-000, Brasil. \\ scfuchs@terra.com.br
}

\begin{abstract}
The association between clustering of risk factors and self-reported cardiovascular disease among women was investigated in a cross-sectional study using a multistage populationbased sample. Participants were interviewed at home about diabetes mellitus, physical activity, and diet pattern. Hypertension was defined as blood pressure $\geq 140 / 90 \mathrm{mmHg}$ or use of anti-hypertensive medication. Cardiovascular disease included self-reported myocardial infarction, heart failure, coronary artery bypass surgery, and stroke. A sample of 1,007 women from Porto Alegre, Southern Brazil, mostly white (73\%), $44.8 \pm 0.8$ years old, and with $9.3 \pm 0.3$ years of schooling was investigated. Hypertension, diabetes mellitus, obesity, low fruit and vegetable intake, and lack of vigorous or moderate physical activity were clustered into a combination of risk factors, which were independently associated with self-reported cardiovascular disease. The main cluster included hypertension and diabetes, accounting for an independent risk ratio of 8.5 (95\%CI: 3.0-24.5). Clustering of cardiovascular risk factors is strongly associated with selfreported cardiovascular disease among women.
\end{abstract}

Nutritional Epidemiology; Cardiovascular Diseases; Women's Health

\author{
Sandra Costa Fuchs 1 \\ Leila Beltrami Moreira 2,3 \\ Susi Alves Camey 4 \\ Marina Beltrami Moreira 3 \\ Flávio Danni Fuchs 3
}

\section{Introduction}

Most mortality due to non-communicable diseases is attributable to cardiovascular diseases, which accounted for 16.7 million deaths in 20051 . By 2020, the mortality burden from non-communicable diseases is expected to occur mostly in low and middle-income countries, where chronic diseases will be the leading cause of death. Estimates are that $71 \%$ of deaths from ischemic heart disease, $75 \%$ from stroke, and $70 \%$ from diabetes mellitus will occur in developing countries 2 .

Cardiovascular diseases and diabetes mellitus have common risk factors, such as unhealthy lifestyle, including overweight and obesity, lack of vigorous or moderate physical activity, and unhealthy diet 3 . The escalating obesity trend affects more than one-fifth of adult women in various countries, and diabetes mellitus is increasing sharply in both developed and developing countries 4 . The prevalence of diabetes is growing among relatively young and productive populations in developing countries ${ }^{4}$.

According to the INTERHEART study ${ }^{5}$, nine potentially modifiable risk factors accounted for over $90 \%$ of the risk for the first acute myocardial infarction. While the overall effect on acute myocardial infarction was detected worldwide for men and women, the impact on women (94\%) surpassed that for men (90\%) 5 . In addition, data from Finland have shown that the risk of type-2 diabetes was equivalent to previous signs of cor- 
onary heart disease for dying of coronary heart disease, and that women were at higher risk than men ${ }^{6}$. In Norway, ischemic heart disease mortality among subjects without coronary heart disease and diabetes was twice as high in men; and this difference was attenuated in the presence of previous coronary heart disease or diabetes, and particularly if both conditions were present 7 .

Among other traditional risk factors for coronary heart disease, two factors (high blood pressure and alcohol abuse) have been identified as independent predictors 8 , but most risk factors tend to cluster within subjects 9 in specific multiple combinations 10,11. A World Health Organization expert panel identified dietary habits as a major modifiable determinant of chronic diseases, having a long-lasting effect capable of shaping the development of cardiovascular disease and diabetes later in life 9 .

This report analyzes the clustering of diabetes mellitus, hypertension, and unhealthy lifestyle factors such as low fruit and vegetable intake, obesity, alcohol abuse, smoking, and lack of vigorous or moderate physical activity as risk factors for coronary heart disease, in a population-based study of women participating in the Syndrome of Obesity and Risk Factors for Cardiovascular Disease Study (SOFT Study), in southern Brazil. The SOFT study included a representative sample of adolescents, adults, and elderly from Porto Alegre, Rio Grande do Sul State, investigating risk factors and cardiovascular disease.

\section{Participants and methods}

This cross-sectional study investigated adults (18-90 years of age) living in Porto Alegre, a State capital with more than 1.5 million inhabitants and a health development index of 0.800 , in 2005, located in southern Brazil. Subjects were selected by multistage population-based sampling, based on geographic subdivisions of the city, defined by the Brazilian Institute of Geography and Statistics (IBGE) 12. A systematic random sample of 106 census tracts was selected from a total of 2,157 , followed by a simple random sampling of one block in each tract, and a systematic sampling of 32 houses from each block. Prior to data collection, the households were visited by the supervisors in order to inform the inhabitants and provide data to create the age strata. A different sampling design was employed for each stratum. Among adults 18 to 59 years of age, sampling was proportional to the size, and in the 60-to-90-year bracket all participants were sampled. At each sampling frame a probability of selection was calculated to conduct the analysis taking into ac- count the effect of design and using the statistical tests in the complex sample module of the Statistical Program for Social Sciences version 16.0 (SPSS Inc., Chicago, USA).

The research team included two coordinators, eight supervisors, and fifty certified interviewers that interviewed participants at home using a standardized questionnaire, which included assessment of demographic characteristics (age and skin color) and questions pertaining to education (years of schooling), marital status, lifestyle, and self-reported diseases.

Demographic data were gathered by self-report skin color, and age was calculated subtracting birth from interview date. Marital status was reported as single or never married, married or living with a partner, separated or divorced, and widowed. The last two categories were collapsed for the data analysis.

Usual daily alcohol consumption was determined through the type, quantity, and frequency of each beverage consumed in the previous 12 months 13 . Women who consumed $15 \mathrm{~g}$ of ethanol or more per day were classified as alcohol abusers.

Subjects who reported having smoked at least 100 cigarettes during their lifetime were identified as ever smoking. Current smokers were those who reported smoking every day or some days at the time of the interview 14 .

Physical activity was evaluated by time spent (in minutes) and frequency (days) of walking, moderate-intensity, and vigorous-intensity activities in the "last seven days", ascertained by interview, and using the short version of the International Physical Activity Questionnaire (IPAQ). Physical activity was categorized as absence versus presence of vigorous or moderate physical activity 15,16 .

Fruit and vegetable intake was assessed through a food-frequency questionnaire with questions on the consumption of 26 fruits and 22 vegetables. For each fruit or vegetable, participants were asked how often, how much, and how many standard units or portions were consumed on average, during the months of the previous year. Answers to the food items were converted to average daily intake of each item and added to compute the total fruit and vegetable intake. The cutoff point for low fruit and vegetable intake was defined as less than eight servings daily, as recommended by the DASH Eating Plan (Dietary Approaches to Stop Hypertension) for a 2,000 calorie diet 17 .

Diabetes mellitus was defined as subject's report of a physician's diagnosis of diabetes or use of medication for diabetes. Blood pressure was measured with a validated automatic device 
(OMRON-CP705, Dupont, France) according to guidelines 18. Hypertension was defined as the average of four blood pressure measurements $\geq 140 / 90 \mathrm{mmHg}$, taken four times at one single visit, or the use of blood pressure-lowering medication ${ }^{3}$

Weight $(\mathrm{kg})$ was measured (with subject in light clothing and barefoot) to the nearest 100 $\mathrm{g}$ with a scale $\left(\right.$ Plenna ${ }^{\circledR}$, model TINN 00088 Plenna - S.A., São Paulo, Brazil), and height (cm) was measured maintaining the Frankfort plane, to the nearest $0.1 \mathrm{~cm}$. Body mass index [BMI = weight $(\mathrm{kg}) /$ height $(\mathrm{m})^{2}$ ] was calculated and the cutoff value for obesity was $B M I \geq 30 \mathrm{~kg} / \mathrm{m}^{2}$.

Clustering of lifestyle risk factors was determined, including smoking, abusive alcohol consumption, obesity, low fruit and vegetable intake, lack of vigorous or moderate physical activity, hypertension, and diabetes. Characteristics associated with increased risk of cardiovascular disease in the age-adjusted analysis were selected in order to compute the main cluster of risk factors ( $p$-value $<0.2$ required). In order to produce a robust variable for clustering of risk factors, the categories with few participants were collapsed. In addition, the association with cardiovascular disease was investigated for other predefined clusters of risk factors, such as: hypertension and diabetes; low fruit and vegetable intake, lack of vigorous or moderate physical activity and obesity; and low fruit and vegetable intake, lack of vigorous or moderate physical activity and smoking.

Cardiovascular disease was defined as a composite endpoint including self-report of ever being diagnosed (by a physician) with myocardial infarction, heart failure, stroke or had coronary artery bypass surgery categorized as present or absent.

A sample size of 676 women was estimated to detect a prevalence ratio of at least 1.8, with $80 \%$ power and $5 \%$ significance level (two-tailed) for a prevalence of self-reported cardiovascular disease of $12 \%$ among unexposed and $21 \%$ among exposed, with a 3:1 ratio. In order to account for the effect design in the data analysis and losses, the sample was increased to 1,007 women. Epi Info 2000 (Centers for Disease Control and Prevention, Atlanta, USA), Statcalc procedure, version 3.3.2 (http://www.ucs.louisiana.edu/ rxk4695/StatCalc.htm), was used for sample size calculation.

A conceptual model using a hierarchical procedure was adopted in the data analysis to take confounding factors into account. The construction of the hierarchical model has been described in detail elsewhere 19. Briefly, independent variables were grouped into different hierarchical levels of determination, ranging from distal determinants such as socioeconomic characteristics (years of schooling and marital status); demographic factors (age and skin color), leading to proximal lifestyle risk factors (smoking, abusive alcohol consumption, obesity, low fruit and vegetable intake, and lack of vigorous or moderate physical activity), and to direct determinants (hypertension and diabetes) of cardiovascular disease. Hypercholesterolemia, which could be situated as a determinant of cardiovascular disease, acts partially through low fruit and vegetable consumption. At each hierarchical level, one regression equation was fitted including the confounding factors: age and skin color (demographic factors) and socioeconomic status and lifestyle risk factors, including the variables associated with selfreported cardiovascular disease in the age-adjusted analyses ( $p$ level $<0.2$ was required). Data were analyzed using the SPSS (version 13), using the complex sample module in order to adjust for the complex multistage sample design. Means and standard errors $( \pm$ SE) or percentages with $95 \%$ confidence intervals (CI) were described for each risk factor. Point prevalence rates of selfreported cardiovascular disease by category of risk factor were estimated using the Pearson chisquared test, and the risk ratios for self-reported cardiovascular disease, assessed by Cox regression model adjusted for age, skin color, and other confounding variables.

The Institutional Review Board of the University Hospital in Porto Alegre [Hospital de Clínicas de Porto Alegre] approved the protocol, and all participants provided informed consent.

\section{Results}

Table 1 shows the characteristics of the 1,007 women enrolled in the SOFT study. The comparison of these characteristics with those from the national census showed that the sample was representative of adult women from Porto Alegre. Most were white (73\%), approximately $25 \%$ were under 30 years of age, and $20 \%$ were 60 to 90 years old. Among those who had ever smoked, $16.7 \%$ were former smokers and $23.6 \%$ current smokers, and $7.9 \%$ consumed 15 grams or more of ethanol daily.

The overall prevalence of self-reported cardiovascular disease was $6.3 \%$ (95\%CI: 4.7-7.8). Table 2 shows the prevalence of self-reported cardiovascular disease according to unhealthy lifestyle risk factors and among women with diabetes and hypertension. Age was strongly associated with self-reported cardiovascular disease, mainly in the highest category, and there was an 
Table 1

Characteristics of women from the Syndrome of Obesity and Risk Factors for Cardiovascular Disease Study (SOFT study), 2007. ( $N=1,007$ )

\begin{tabular}{|c|c|}
\hline & $\begin{array}{c}\text { Mean } \pm \text { SD or } \\
\text { percentage }(95 \% \mathrm{Cl}) \text { * }\end{array}$ \\
\hline Age (years) & $44.8 \pm 0.8$ \\
\hline Years of schooling & $9.3 \pm 0.3$ \\
\hline Non-white skin color & $27.0(22.1-32.0)$ \\
\hline \multicolumn{2}{|l|}{ Marital status } \\
\hline Single & $29.3(25.4-33.2)$ \\
\hline Married & $43.2(39.2-47.2)$ \\
\hline Divorced & $27.5(24.3-30.8)$ \\
\hline Ever smoked & $40.3(36.7-43.9)$ \\
\hline Abusive alcohol consumption ** & $7.9(5.9-10.0)$ \\
\hline 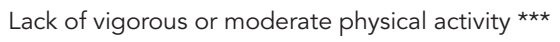 & $26.9(22.9-31.4)$ \\
\hline Low fruit and vegetable intake \# & $27.9(23.8-32.3)$ \\
\hline Obesity \#\# & $22.5(19.4-25.7)$ \\
\hline Hypertension \#\#\# & $29.0(25.8-32.4)$ \\
\hline Diabetes mellitus $\S$ & $7.3(5.7-8.9)$ \\
\hline
\end{tabular}

* Estimates adjusted by effect design;

** $\geq 15$ grams of ethanol/day;

*** Moderate or vigorous activities according to the International Physical Activity Question-

naire;

$\# \geq 8$ portions of fruits or vegetables per day;

\#\# Body mass index $\geq 30 \mathrm{~kg} / \mathrm{m}^{2}$;

\#\#\# Blood pressure $\geq 140 / 90 \mathrm{mmHg}$ or use of medication for hypertension;

$\S$ Previous diagnosis by a physician or use of medication for diabetes.

inverse association with years of schooling. These associations appear to have a dose-response relationship. Single or never married women had a lower prevalence of self-reported cardiovascular disease as compared to divorcees and widows. Smoking and low fruit and vegetable intake were not associated with self-reported cardiovascular disease, while women with alcohol abuse presented lower prevalence of self-reported cardiovascular disease than those with no (or only social) alcohol consumption.

Cox regression analysis confirmed that age was an independent risk factor for self-reported cardiovascular disease (Table 3). Marital status lost its explanatory power after adjusting for demographic confounding factors. Hypertension was the strongest predictor of self-reported cardiovascular disease, even after adjusting for confounding, while diabetes, obesity, and other risk factors were no longer significantly associated with self-reported cardiovascular disease. As the result of the age-adjusted analysis, low fruit and vegetable intake, lack of vigorous or moderate physical activity, obesity, hyperten- sion, and diabetes were used to compute the main clustering of risk factors, categorized into 0-1, 2, 3, and 4-5.

Approximately $12.5 \%$ (95\%CI: $10.0-15.6)$ of the women had no risk factors, $39.1 \%(95 \% \mathrm{CI}$ : 35.4-43.1) had one risk factor, and 5.3\% (95\%CI: 4.2-6.7) had a cluster of four or five risk factors. Table 4 shows the prevalence of clustered risk factors and the association between various sets of risk factors and self-reported cardiovascular disease. There was a dose-response curve in the association between self-reported cardiovascular disease and the number of clustered risk factors. Women exposed to four or five clustered risk factors were about seven times more likely to have self-reported cardiovascular disease than those with one or no risk factors. Clustering of four or five risk factors presented a strong effect, but lower than that of hypertension and diabetes. Clustering of unhealthy lifestyle factors including obesity, low fruit and vegetable intake, and lack of vigorous or moderate physical activity lost most of its explanatory power after adjusting for confounding.

\section{Discussion}

The aim of this study was to assess the cardiovascular risk conferred by clustering hypertension, diabetes mellitus, alcohol abuse, obesity, smoking, low fruit and vegetable intake, and lack of vigorous or moderate physical activity among women from a general population, aged 18-90 years. Clustering of four or five risk factors was a strong predictor of self-reported cardiovascular disease, independently of age, skin color, and alcohol abuse. However, the set of risk factors including hypertension, diabetes, obesity, low fruit and vegetable intake, and lack of vigorous or moderate physical activity showed a lower association with self-reported cardiovascular disease than the cluster of hypertension and diabetes alone. This was not surprising, since hypertension is prevalent and has accounted for $62 \%$ of stroke and $49 \%$ of ischemic heart disease 3 , but the independent clustered risk ratio of hypertension and diabetes was striking. The present study confirmed the individual association between hypertension and diabetes and incident cardiovascular disease, which has been described previously in the same population base 8,20 .

Most women had no (12.5\%) or one (39.1\%) risk factor, and approximately $5.3 \%$ had four or five clustered risk factors, unlike the prevalence described in a Dutch general population, aged 20-59 years 21 and in women from the $2001 \mathrm{Na}$ tional Health Interview Survey 22. Meanwhile, our 
Risk factors for cardiovascular disease among women 18-90 years old from the Syndrome of Obesity and Risk Factors for Cardiovascular Disease Study (SOFT study), 2007. ( $\mathrm{N}=1,007)$.

\begin{tabular}{|c|c|c|c|}
\hline & $\begin{array}{l}\text { Prevalence of cardiovascular } \\
\text { disease }(95 \% \mathrm{Cl}) \text { * }\end{array}$ & $\operatorname{RR}(95 \% \mathrm{Cl}) *, * \star$ & $\mathrm{p}$-value \\
\hline Age (years) & & & $<0.001$ \\
\hline $18-49$ & $1.5(0.7-3.3)$ & 1.0 & \\
\hline $50-64$ & $8.6(4.9-14.9)$ & $6.1(2.2-16.7)$ & \\
\hline $65-90$ & $23.1(18.5-28.4)$ & $17.6(7.5-41.5)$ & \\
\hline Years of schooling & & & $<0.001$ \\
\hline $0-4$ & $13.8(9.9-18.9)$ & $4.0(2.1-7.6)$ & \\
\hline $5-8$ & $6.6(4.3-10.0)$ & $1.9(1.01-3.4)$ & \\
\hline$\geq 9$ & $3.6(2.2-5.8)$ & 1.0 & \\
\hline Skin color & & & 0.13 \\
\hline White & $5.5(3.9-7.7)$ & 1.0 & \\
\hline Non-white & $8.3(5.6-12.2)$ & $1.5(0.9-2.7)$ & \\
\hline Marital status & & & $<0.001$ \\
\hline Single & $2.8(1.4-5.5)$ & 1.0 & \\
\hline Married & $4.6(2.9-7.2)$ & $1.7(0.7-3.9)$ & \\
\hline Divorced or widow & $12.6(9.3-16.8)$ & $4.7(2.2-10.3)$ & \\
\hline Smoking & & & 0.6 \\
\hline No & $6.6(5.0-8.7)$ & 1.0 & \\
\hline Ever smoked & $5.8(4.0-8.4)$ & $0.9(0.6-1.4)$ & \\
\hline Alcohol consumption & & & 0.02 \\
\hline None or social & $6.8(5.3-8.6)$ & 1.0 & \\
\hline Abusive & $0.7(0.1-4.8)$ & $0.1(0.01-0.7)$ & \\
\hline Low fruit and vegetable intake & & & 0.3 \\
\hline No & $4.9(3.0-7.9)$ & 1.0 & \\
\hline Yes & $6.8(5.0-9.2)$ & $1.4(0.7-2.6)$ & \\
\hline Lack of vigorous or moderate physical activity & & & 0.002 \\
\hline No & $4.8(3.4-6.8)$ & 1.0 & \\
\hline Yes & $10.3(7.4-14.0)$ & $2.2(1.4-3.6)$ & \\
\hline Obesity & & & $<0.001$ \\
\hline No & $4.5(3.3-6.2)$ & 1.0 & \\
\hline Yes & $12.2(8.6-16.9)$ & $2.8(1.8-4.4)$ & \\
\hline Hypertension & & & $<0.001$ \\
\hline No & $1.1(0.6-2.0)$ & 1.0 & \\
\hline Yes & $18.9(14.6-24.0)$ & $14.1(7.8-25.5)$ & \\
\hline Diabetes mellitus & & & $<0.001$ \\
\hline No & $5.2(3.9-7.0)$ & 1.0 & \\
\hline Yes & $19.6(13.0-28.5)$ & $4.1(2.3-7.0)$ & \\
\hline
\end{tabular}

* Estimates adjusted by effect design;

** Non-adjusted risk ratios were calculated using Cox regression model.

study confirmed the low prevalence of four simultaneous lifestyle risk factors detected in the English population 23.

Smoking is a well-known cardiovascular risk factor. However, neither current nor former smoking was associated with self-reported cardiovascular disease in this population, as has been shown ${ }^{8}$. Possible explanations are chance and the possibility that most former smokers quit smoking after presenting a cardiovascular event.
Even though smoking was not associated with self-reported cardiovascular disease, it was included in the cluster with low fruit and vegetable intake and lack of vigorous or moderate physical activity, since smoking was clustered with unhealthy behaviors in the English population 23. In this study, we were not able to confirm that the cluster of smoking, low fruit and vegetable intake, and lack of vigorous or moderate physical activity predicts self-reported cardiovascular disease. 
Cox regression model of risk factors for cardiovascular disease among women from Syndrome of Obesity and Risk Factors for Cardiovascular Disease Study (SOFT study), 2007. ( $N=1,007)$.

\begin{tabular}{|c|c|c|}
\hline & $\mathrm{RR}(95 \% \mathrm{Cl}) *, \star \star$ & $\mathrm{RR}(95 \% \mathrm{Cl})$ * \\
\hline \multicolumn{3}{|l|}{ Age (years) } \\
\hline $18-49$ & 1.0 & $1.0 * \star \star$ \\
\hline $50-64$ & $6.1(2.2-16.7)$ & $6.4(2.4-17.2)$ \\
\hline $65-90$ & $17.6(7.5-41.5)$ & $18.1(7.7-42.6)$ \\
\hline$p$-value & $<0.001$ & $<0.001$ \\
\hline \multicolumn{3}{|l|}{ Years of schooling } \\
\hline $0-4$ & $1.7(0.9-3.2)$ & $1.4(0.7-2.8)$ \\
\hline $5-8$ & $1.3(0.8-2.3)$ & $1.2(0.7-2.1)$ \\
\hline$\geq 9$ & 1.0 & $1.0 \#$ \\
\hline$p$-value & 0.3 & 0.6 \\
\hline Non-white skin color & $1.7(1.0-2.9)$ & $1.7(1.0-2.9) * \star$ \\
\hline $\mathrm{p}$-value & 0.047 & 0.047 \\
\hline \multicolumn{3}{|l|}{ Marital status } \\
\hline Single & 1.0 & $1.0 \#$ \\
\hline Married & $1.1(0.5-2.5)$ & $1.1(0.5-2.5)$ \\
\hline Divorced & $1.6(0.7-3.6)$ & $1.5(0.7-3.5)$ \\
\hline p-value & 0.3 & 0.4 \\
\hline Ever smoked & $1.0(0.7-1.6)$ & $1.1(0.7-1.7) \# \#$ \\
\hline $\mathrm{p}$-value & 0.8 & 0.6 \\
\hline Abusive alcohol consumption & $0.1(0.02-0.9)$ & $0.2(0.03-0.99) \# \#$ \\
\hline $\mathrm{p}$-value & 0.04 & 0.048 \\
\hline Low fruit and vegetable intake & $1.6(0.9-3.0)$ & $1.4(0.7-2.7) \# \#$ \\
\hline p-value & 0.1 & 0.3 \\
\hline Lack of vigorous or moderate physical activity & $1.5(0.9-2.3)$ & $1.3(0.8-2.1) \# \#$ \\
\hline p-value & 0.12 & 0.2 \\
\hline Obesity & $1.9(1.2-2.9)$ & $1.4(0.9-2.2) \# \#$ \\
\hline p-value & 0.003 & 0.12 \\
\hline Hypertension & $6.7(3.0-15.0)$ & 5.9 (2.6-13.5) \#\#\# \\
\hline $\mathrm{p}$-value & $<0.001$ & $<0.001$ \\
\hline Diabetes mellitus & $1.8(1.0-3.3)$ & $1.6(0.9-2.8) \# \# \#$ \\
\hline p-value & 0.07 & 0.13 \\
\hline
\end{tabular}

* Estimates adjusted by effect design;

** RR adjusted for age;

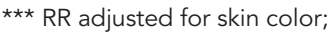

\# RR adjusted for age and skin color;

\#\# RR adjusted for age, skin color, low fruit and vegetable intake, lack of vigorous or moderate physical activity, obesity, and alcohol consumption;

\#\# RR adjusted for all variables of the last model and additionally adjusted for hypertension and diabetes.

On the other hand, after replacing smoking with obesity, the cluster with low fruit and vegetable diet and lack of vigorous or moderate physical activity lost most of its explanatory power.

Alcohol consumption, particularly wine in moderate amounts, has been associated with lower incidence of coronary heart disease. In
Porto Alegre, alcohol consumption was associated with increased incidence of cardiovascular disease in a cohort study 8 . Taken together, the risk in the follow-up study and protection in the present cross-sectional survey may be secondary to random variation around the null association. 
Cox regression model for clustering of risk factors for cardiovascular disease among women from Syndrome of Obesity and Risk Factors for Cardiovascular Disease Study (SOFT study), 2007. ( $\mathrm{N}=1,007)$.

\begin{tabular}{|c|c|c|c|}
\hline & $\%$ & $\operatorname{RR}(95 \% \mathrm{Cl}) *, \star \star$ & $\mathrm{RR}(95 \% \mathrm{Cl}) * *$ \\
\hline \multicolumn{4}{|c|}{ Main clustering of risk factors $* \star \star$} \\
\hline $0-1$ & 52.1 & 1.0 & 1.0 \# \\
\hline 2 & 30.8 & $2.3(1.01-5.1)$ & $2.2(1.0-4.8)$ \\
\hline 3 & 12.0 & $3.6(1.6-8.2)$ & $3.3(1.5-7.7)$ \\
\hline $4-5$ & 5.1 & $7.2(3.0-17.2)$ & $6.6(2.8-15.8)$ \\
\hline p-value & & $<0.001$ & $<0.001$ \\
\hline \multicolumn{4}{|c|}{ Clustering of hypertension and diabetes } \\
\hline 0 & 68.3 & 1.0 & $1.0 \# \#$ \\
\hline 1 & 27.2 & $5.8(2.6-13.1)$ & $5.2(2.2-11.8)$ \\
\hline 2 & 4.5 & $9.4(3.4-26.5)$ & $8.5(3.0-24.5)$ \\
\hline$p$-value & & $<0.001$ & $<0.001$ \\
\hline \multicolumn{4}{|c|}{$\begin{array}{l}\text { Clustering of obesity, low fruit and vegetable intake, } \\
\text { and lack of vigorous or moderate physical activity }\end{array}$} \\
\hline 0 & 17.0 & 1.0 & $1.0 \#$ \\
\hline 1 & 49.9 & $1.5(0.7-3.3)$ & $1.4(0.6-3.1)$ \\
\hline 2 & 27.6 & $2.2(1.0-5.0)$ & $2.0(0.8-4.6)$ \\
\hline 3 & 5.5 & $4.0(1.5-10.2)$ & $3.6(1.3-9.6)$ \\
\hline $\mathrm{p}$-value & & 0.02 & 0.046 \\
\hline \multicolumn{4}{|c|}{$\begin{array}{l}\text { Clustering of smoking, low fruit and vegetable intake, } \\
\text { and lack of vigorous or moderate physical activity }\end{array}$} \\
\hline 0 & 12.8 & 1.0 & $1.0 \# \#$ \\
\hline 1 & 43.6 & $1.2(0.5-2.9)$ & $0.8(0.3-1.8)$ \\
\hline 2 & 35.1 & $1.9(0.7-4.9)$ & $0.8(0.4-1.7)$ \\
\hline 3 & 8.5 & $2.0(0.7-5.7)$ & $1.1(0.6-2.3)$ \\
\hline $\mathrm{p}$-value & & 0.5 & 0.5 \\
\hline
\end{tabular}

* Risk ratio adjusted for age;

** Estimates adjusted by effect design;

*** Lack of vigorous or moderate physical activity, obesity, hypertension and diabetes;

\# RR adjusted for age and skin color, and abusive alcohol consumption;

\#\#R adjusted for age, skin color, obesity, and abusive alcohol consumption.

Our study has some weakness that should be addressed. The non-directional cross-sectional design prevents inferring causality, but the risk factors that we identified were consistent with those found in cohort studies and clinical trials. Self-reporting of some risk factors and cardiovascular disease may be subject to recall bias. The potential for underreporting of smoking and alcohol abuse is well-known 24 . Meanwhile, hypertension and obesity, which are more commonly underreported 24 , were directly determined, and self-reported diabetes is reliable 24 . The risk of cardiovascular disease due to diabetes, assessed by self-reported or fasting plasma glucose, showed no marked difference 25. Hypercholesterolemia, another risk factor for cardiovascular disease, was not inves- tigated by self-reporting due to the limited number of participants aware of this risk factor 26 . Major cardiovascular events are probably less susceptible to recall bias, and there is no reason to suppose that measurement bias would be directional. Heart failure, however, could be secondary to non-atherosclerotic cardiovascular disease such as rheumatic fever or Chagas' disease, but hypertension and coronary heart disease are the main causes. Another potential limitation of our study is that we included diet, physical activity, and BMI (all measures related to energy balance) in the lifestyle-related risk factors, which could overestimate the role of energy balance.

The strengths of our study include the large sample of women randomly selected from the 
general population and the evaluation of clustering with cardiovascular events as the outcome. Most studies on clustering of cardiovascular risk factors 10,11,21 have been restricted to the evaluation of simultaneous occurrence of unhealthy behaviors.
In conclusion, we demonstrated that clustering of cardiovascular factors is strongly associated with self-reported cardiovascular disease in women in Porto Alegre. A multidimensional model of health intervention is recommended, particularly focusing on hypertension and diabetes and their associated risk factors.

\section{Resumo}

A associação entre agregação de fatores de risco e doença cardiovascular auto-identificada entre mulheres fo $i$ investigada em estudo transversal, utilizando amostra de base populacional, por estágios múltiplos. Entrevista domiciliar investigou diagnóstico prévio de diabetes mellitus, atividade física e padrão alimentar. Hipertensão foi definida por pressão arterial $\geq 140 / 90 \mathrm{mmHg}$ ou uso de anti-hipertensivo. Doença cardiovascular auto-identificada foi composta por diagnósticos prévios de infarto do miocárdio, insuficiência cardíaca e acidente vascular encefálico ou realização de cirurgia de revascularização miocárdia. Estudaram-se 1.007 mulheres de Porto Alegre, Rio Grande do Sul, Brasil, predominantemente brancas (73\%), com 44, $8 \pm 0,8$ anos e 9,3 \pm 0,3 anos de escolaridade. Agregação de hipertensão, diabetes mellitus, obesidade, baixo consumo de frutas e vegetais e ausência de atividade física vigorosa ou moderada associaram-se independentemente com doença cardiovascular auto-identificada. A principal agregação foi hipertensão e diabetes com razão de prevalência = 8,5 (IC95\%: 4,6-49,1). A agregação de fatores de risco cardiovascular está fortemente associada com doença cardiovascular auto-identificada entre as mulheres.

Epidemiologia Nutricional; Doenças Cardiovasculares; Saúde da Mulher

\section{Contributors}

S. C. Fuchs and L. B. Moreira designed the study, supervised the data acquisition, analyzed and interpreted the data, and wrote the manuscript. S. A. Camey took part in the analysis and drafting of the manuscript. M. B. Moreira participated in the data collection, systematization and analysis. F. D. Fuchs was one of the principal investigators, taking part in the design, data analysis and interpretation, and writing of the manuscript. All the authors read and approved the final version.

\section{Acknowledgments}

The research project received financing from the Brazilian National Research Council (CNPq), including a grant from the Program for Centers of Excellence (PRONEX), and the Fund to Support Research (FIPE) through the University Hospital in Porto Alegre. The authors wish to thank OMRON Corporation for donating some of the equipment used in the project and Sergio L. Bassanesi for his technical support in constructing the databases and locating the Brazilian national statistics. 


\section{References}

1. Anderson GF, Chu E. Expanding priorities: confronting chronic disease in countries with low income. N Engl J Med 2007; 356:290-11.

2. World Health Organization. Preventing chronic diseases: a vital investment. Geneva: World Health Organization; 2005. (WHO Global Report).

3. World Health Organization. The World Health Report 2002: reducing risks, promoting healthy life. Geneva: World Health Organization; 2002.

4. International Diabetes Federation. Diabetes atlas, 2003. http://www.eatlas.idf.org/webdata/docs/ Atlas\%202003-Summary.pdf (accessed on 24/ Nov/2007).

5. Yusuf S, Hawken S, Ôunpuu S, Dans T, Avezum A, Lanas F, et al. Effect of potentially modifiable risk factors associated with myocardial infarction in 52 countries (INTERHEART study): case-control study. Lancet 2004; 364:937-52.

6. Juutilainen A, Lehto S, Rönnemaa T, Pyörälä K, Laakso M. Type 2 diabetes as a "coronary heart disease equivalent": an 18-year prospective population-based study in Finnish subjects. Diabetes Care 2005; 28:2901-7.

7. Dale AC, Nilsen TI, Vatten L, Midthjell K, Wiseth R. Diabetes mellitus and risk of fatal ischaemic heart disease by gender: 18 years follow-up of 74,914 individuals in the HUNT 1 Study. Eur Heart J 2007; 28:2924-9.

8. Moraes RS, Fuchs FD, Moreira LB, Wiehe M, Pereira GM, Fuchs SC. Risk factors for cardiovascular disease in a Brazilian population-based cohort study. Int J Cardiol 2003; 90:205-11.

9. World Health Organization. Report of a WHO study group. Diet, nutrition, and the prevention of chronic diseases. Geneva: World Health Organization; 1990. (WHO Technical Report Series, 797).

10. Poortinga W. The prevalence and clustering of four major lifestyle risk factors in an English adult population. Prev Med 2007; 44:124-8.

11. Berrigan D, Dodd K, Troiano RP, Krebs-Smith SM, Barbash RB. Patterns of health behavior in U.S. adults. Prev Med 2003; 36:615-23.

12. Instituto Brasileiro de Geografia e Estatística. Censo demográfico 2000. http://www.ibge.gov.br/ home/estatistica/populacao/default_censo_2000. shtm (accessed on 05/Jul/2007).

13. Moreira LB, Fuchs FD, Moraes RS, Bredemeier M, Cardozo S, Fuchs SC, et al. Alcoholic beverage consumption and associated factors in Porto Alegre, a southern Brazilian city: a population-based survey. J Stud Alcohol 1996; 57:253-9.

14. Centers for Disease Control and Prevention. Prevalence of current cigarette smoking among adults and changes in prevalence of current and some day smoking-United States, 1996-2001. JAMA 2003; 289:2355-6.
15. Craig CL, Marshall AL, Sjöström M, Bauman AE, Booth ML, Ainsworth BE, et al. International physical activity questionnaire: 12-country reliability and validity. Med Sci Sports Exerc 2003; 35: 1381-95.

16. Hallal PC, Matsudo SM, Matsudo VK, Araújo TL, Andrade DR, Bertoldi AD. Physical activity in adults from two Brazilian areas: similarities and differences. Cad Saúde Pública 2005; 21:73-80.

17. U. S. Department of Health and Human Services. Dietary guidelines for Americans 2005. Appendix A. Eating patterns. http://www.health.gov/dietary guidelines/dga2005/document/html/AppendixA. htm\#appA1 (accessed on 11/Mar/2007).

18. O'Brien E, Mee F, Atkins N, Thomas M. Evaluation of three devices for self-measurement of blood pressure according to the revised British Hypertension Society Protocol: the Omron HEM-705CP, Philips HP5332, and Nissei DS-175. Blood Press Monit 1996; 1:55-61.

19. Victora CG, Huttly SR, Fuchs SC, Olinto MT. The role of conceptual frameworks in epidemiological analysis: a hierarchical approach. Int J Epidemiol 1997; 26:224-7.

20. Moreira LB, Fuchs SC, Wiehe M, Picon R, Moreira MB, Neyloff JL, et al. Cardiovascular consequences of diabetes mellitus in Brazil: results of a population-based longitudinal study. Eur Heart J 2007; 28:4079.

21. Schuit AJ, van Loon AJ, Tijhuis M, Ocké M. Clustering of lifestyle risk factors in a general adult population. Prev Med 2002; 35:219-24.

22. Fuchs FD, Chambless LE. Is the cardioprotective effect of alcohol real? Alcohol 2007; 41:399-402.

23. Fine LJ, Philogene GS, Gramling R, Coups EJ, Sinha S. Prevalence of multiple chronic disease risk factors. 2001 National Health Interview Survey. Am J Prev Med 2004; 27(2 Suppl):18-24.

24. Newell SA, Girgis A, Sanson-Fisher RW, Savolainen NJ. The accuracy of self-reported health behaviors and risk factors relating to cancer and cardiovascular disease in the general population: a critical review. Am J Prev Med 1999; 17:211-29.

25. Huxley R, Barzi F, Woodward M. Excess risk of fatal coronary heart disease associated with diabetes in men and women: meta-analysis of 37 prospective cohort studies. BMJ 2006; 332:73-8.

26. Johansson J, Hellenius ML, Elofsson S, Krakau I. Self-report as a selection instrument in screening for cardiovascular disease risk. Am J Prev Med 1999; 16:322-4.

Submitted on 29/Nov/2007

Final version resubmitted on 06/Mar/2008

Approved on 10/Mar/2008 